\title{
Cardiac risk assessment in asymptomatic diabetes: Combing different imaging modalities and surrogate markers?
}

\author{
Arthur J. H. A. Scholte, MD, PhD
}

\section{See related article, pp. 398-406}

The growing number of patients who develop diabetes mellitus (DM) is a great concern for public health care. Type 2 DM comprises $90 \%$ of all diabetic patients worldwide, and is largely the result of excess body weight and physical inactivity. Long term complications of DM include microvascular damage and macrovascular injuries. These complications reduce life expectancy and quality of life, and significantly increase morbidity. Due to the often masked symptoms of DM, the disease may be diagnosed several years after onset when complications have already occurred. Often, the prognosis of patients with DM depends on the presence of cardiovascular disease. Coronary artery disease (CAD) is the leading cause of morbidity and mortality in individuals with type 2 DM. ${ }^{1}$ The 10 -year mortality rate in patients with known CAD and diabetes exceeds $70 \% .^{2}$

Some studies suggest that the risk for future cardiac death in patients with diabetes without known CAD is similar to that in non-diabetic patients with overt clinical CAD. ${ }^{2}$ In addition, early and late outcomes of diabetic patients with acute coronary syndromes are worse than those of their non-diabetic counterparts. To compound the problem, myocardial ischemia is often asymptomatic in patients with $\mathrm{DM}$, and CAD is frequently in an advanced state, when becoming clinically manifest. ${ }^{3,4}$ The previously described adverse clinical outcomes in patients with diabetes underscores the need to develop practical approaches to detect CAD in an early stage

From the Department of Cardiology, Leiden University Medical Center, RC, Leiden, The Netherlands.

Reprint requests: Arthur J. H. A. Scholte, MD, PhD, Department of Cardiology, Leiden University Medical Center, Albinusdreef 2, PO Box 9600, 2300, RC, Leiden, The Netherlands; a.j.h.a.scholte@ lumc.nl.

J Nucl Cardiol 2011;18:393-5.

$1071-3581 / \$ 34.00$

Copyright (c) 2011 The Author(s). This article is published with open access at Springerlink.com

doi:10.1007/s12350-011-9366-Z before clinical symptoms occur. Thus, early detection of CAD and myocardial ischemia appears to be important to reduce morbidity and mortality from cardiovascular disease in asymptomatic patients with type 2 DM. Identification of these asymptomatic diabetic patients might be important to intervene early and to increase long term survival. From a management perspective, patients with high risk characteristics on testing for myocardial ischemia may benefit from coronary revascularization. With regard to pharmacological therapy, the knowledge that a patient with diabetes has CAD may indicate the need to initiate or intensify pharmacological therapy with aspirins, statins, and angiotensin converting enzyme (ACE) inhibitors. Results from the BARI 2D trial showed no significantly differences in survival rates as well as in freedom from major cardiovascular events between optimal medical therapy and revascularization. ${ }^{5}$ So, it seems that testing for ischemia should be reserved for selected individuals with a strong suspicion of high risk CAD.

Single photon emission computed tomography (SPECT) myocardial perfusion imaging (MPI) has been used extensively in the detection of (silent) myocardial ischemia in symptomatic as well as asymptomatic patients with DM. Several studies in the literature suggest a high prevalence of abnormal MPI in diabetic patients, ranging from $37 \%$ to $62 \% .^{6-12}$ The same studies furthermore demonstrate, in a mean follow-up of 24-70 months, a hard event rate of $3.6 \%-9.0 \%$ per year in diabetic patients with abnormal MPI. Retrospective database analysis reveals the same percentages of abnormal MPI and hard event rates in symptomatic and asymptomatic patients with diabetes. ${ }^{8-10,12-14}$ Prospective studies in asymptomatic patients with diabetes show a lower prevalence of silent myocardial ischemia ranging from $6 \%$ to $22 \% .{ }^{15-20}$ Differences in design and stress testing methodology may explain these variations in prevalence. One of these prospective studies is the DIAD trial. ${ }^{20}$ The lessons learned from this important trial has been extensively described in this journal. ${ }^{21}$ The authors concluded that routine screening of asymptomatic patients with diabetes was not justified but they also speculated that other imaging studies might provide additional insights into models that might in combination with MPI 
identify subjects at high risk. Anand et al used a stepwise protocol and proved in 510 asymptomatic patients with type $2 \mathrm{DM}$ that initial testing for coronary calcium by electron beam computed tomography and SPECT MPI can optimize the selection of patients who should undergo stress MPI. During follow-up the majority of the events occurred in patients with coronary artery calcium (CAC) score of greater than $400 .{ }^{15}$

In this issue of the Journal, Peix et $\mathrm{al}^{22}$ report the results of an interesting study. They investigated in 59 asymptomatic patients with type $2 \mathrm{DM}$ the prevalence of ischemia detected by SPECT MPI, and compared it to a control group of 42 age and sex matched non-diabetic volunteers, who also had risk factors for CAD. In addition, they explored the relationship between silent ischemia, endothelial dysfunction and the CAC score. Endothelial dysfunction was tested by brachial artery vasodilatation ultrasonography measurement, an indirect measurement of coronary endothelial function. Standard SPECT MPI and CAC score protocols were used. In 20 (34\%) diabetic patients and in $7(17 \%)$ controls perfusion defects were observed. Although the majority of diabetics with abnormal myocardial perfusion had abnormal endothelial dysfunction, there was no significant difference between the groups. Furthermore, as suspected CAC score was significantly higher in the diabetic group. The only variable that was associated significantly with perfusion abnormalities was the presence of diabetes. Although the number of patients is small, this study is the first in which asymptomatic diabetics are compared to matched controls with risk factors for $\mathrm{CAD}$, regarding detection of silent myocardial ischemia. The incidence as well as the extent of myocardial ischemia is within the range of previously mentioned studies. Even though the majority of the patients had extensive number of risk factors for CAD, all were able to perform an exercise test, suggesting a relative "healthy" diabetic population without serious complications such as peripheral artery disease and diabetic neuropathy. The authors explored the interrelationship between myocardial perfusion abnormalities, CAC score and endothelial dysfunction. This relationship is interesting because it may explain the discrepancy between the presence of myocardial perfusion defects and the absence of obstructive epicardial CAD. While among diabetics, $69 \%$ of the patients with abnormal perfusion had endothelial dysfunction, only a small number of diabetics with perfusion abnormalities showed abnormal CAC score. Accordingly, endothelial dysfunction may have a greater impact on myocardial perfusion than the extent of diffuse atherosclerosis. This condition most likely represents an early stage of vascular disease amenable to treatment, and intensification of antiatherogenic therapy seems to be indicated.
Certainly, the DIAD trial showed that intense treatment with statins, aspirin, and ACE inhibitors reduced inducible ischemia in $79 \%$ of asymptomatic diabetic patients. ${ }^{23}$ In this respect it is remarkable to see the low number of patients in the current study of Peix et al who were on these medications.

Considering that in DM, abnormal myocardial perfusion is often observed in the absence of epicardial obstructive CAD, one can wonder whether SPECT MPI in asymptomatic patients with type 2 DM should be accompanied by CAC scoring. Possibly multislice computed tomography coronary angiography could have incremental value in asymptomatic patients with diabetes with abnormal myocardial perfusion. MSCT can differentiate between obstructive epicardial CAD and endothelial dysfunction as the cause of myocardial perfusion abnormalities. However, combining these two cardiac imaging modalities increases health care costs and radiation exposure. Given the increasing prevalence of diabetes it is important first to optimize and intensify pharmacological therapy. Secondly, close and careful follow-up of these patients might reveal that asymptomatic diabetic patients often have atypical angina complaints or dyspnea, and can selectively be referred for further clinical testing of myocardial ischemia. Moreover, is testing with different algorithms still needed to better identify asymptomatic patients with type $2 \mathrm{DM}$ at higher risk?

Although recent ACCF/AHA guidelines suggest that peripheral arterial flow-mediated dilation is not recommended in asymptomatic patients, stress MPI may be considered in asymptomatic patients with diabetes. ${ }^{24}$ Conversely, a recent post hoc analysis of the DIAD study showed that patients with intermediate/high risk baseline risk had a low annual cardiac event rate, which was not altered by routine screening for inducible ischemia. ${ }^{25}$ The current prospective multicenter study is still in progress and by increasing the number of patients it may give answer to the question if we still need to combine different imaging modalities and surrogate markers to identify the high risk asymptomatic patient with type $2 \mathrm{DM}$.

\section{Conflicts of interest}

The author has indicated that they have no financial conflicts of interest.

\section{Open Access}

This article is distributed under the terms of the Creative Commons Attribution Noncommercial License which permits any noncommercial use, distribution, and reproduction in any medium, provided the original author(s) and source are credited. 


\section{References}

1. Consensus development conference on the diagnosis of coronary heart disease in people with diabetes: 10-11 February 1998, Miami, Florida. American Diabetes Association. Diabetes Care 1998;21:1551-59.

2. Haffner SM, Lehto S, Ronnemaa T, Pyorala K, Laakso M. Mortality from coronary heart disease in subjects with type 2 diabetes and in nondiabetic subjects with and without prior myocardial infarction. N Engl J Med 1998;339:229-34.

3. The BARI Investigators. Influence of diabetes on 5-year mortality and morbidity in a randomized trial comparing CABG and PTCA in patients with multivessel disease: The Bypass Angioplasty Revascularization Investigation (BARI). Circulation 1997;96: 1761-9.

4. The BARI Investigators. Seven-year outcome in the Bypass Angioplasty Revascularization Investigation (BARI) by treatment and diabetic status. J Am Coll Cardiol 2000;35:1122-9.

5. Frye RL, August P, Brooks MM, Hardison RM, Kelsey SF, MacGregor JM, et al. A randomized trial of therapies for type 2 diabetes and coronary artery disease. N Engl J Med 2009; 360:2503-15.

6. Berman DS, Kang X, Hayes SW, Friedman JD, Cohen I, Abidov A, et al. Adenosine myocardial perfusion single-photon emission computed tomography in women compared with men. Impact of diabetes mellitus on incremental prognostic value and effect on patient management. J Am Coll Cardiol 2003;41:1125-33.

7. Felsher J, Meissner MD, Hakki AH, Heo J, Kane-Marsch S, Iskandrian AS. Exercise thallium imaging in patients with diabetes mellitus. Prognostic implications. Arch Intern Med 1987;147: 313-7.

8. Giri S, Shaw LJ, Murthy DR, Travin MI, Miller DD, Hachamovitch R, et al. Impact of diabetes on the risk stratification using stress single-photon emission computed tomography myocardial perfusion imaging in patients with symptoms suggestive of coronary artery disease. Circulation 2002;105:32-40.

9. Kang X, Berman DS, Lewin HC, Cohen I, Friedman JD, Germano $\mathrm{G}$, et al. Incremental prognostic value of myocardial perfusion single photon emission computed tomography in patients with diabetes mellitus. Am Heart J 1999;138:1025-32.

10. Miller TD, Rajagopalan N, Hodge DO, Frye RL, Gibbons RJ. Yield of stress single-photon emission computed tomography in asymptomatic patients with diabetes. Am Heart J 2004;147:890-6.

11. Schinkel AF, Elhendy A, van Domburg RT, Bax JJ, Vourvouri EC, Sozzi FB, et al. Prognostic value of dobutamine-atropine stress myocardial perfusion imaging in patients with diabetes. Diabetes Care 2002;25:1637-43.

12. Zellweger MJ, Hachamovitch R, Kang X, Hayes SW, Friedman JD, Germano G, et al. Prognostic relevance of symptoms versus objective evidence of coronary artery disease in diabetic patients. Eur Heart J 2004;25:543-50.

13. Rajagopalan N, Miller TD, Hodge DO, Frye RL, Gibbons RJ. Identifying high-risk asymptomatic diabetic patients who are candidates for screening stress single-photon emission computed tomography imaging. J Am Coll Cardiol 2005;45:43-9.
14. De Lorenzo A, Lima RS, Siqueira-Filho AG, Pantoja MR. Prevalence and prognostic value of perfusion defects detected by stress technetium-99m sestamibi myocardial perfusion single-photon emission computed tomography in asymptomatic patients with diabetes mellitus and no known coronary artery disease. Am J Cardiol 2002;90:827-32.

15. Anand DV, Lim E, Hopkins D, Corder R, Shaw LJ, Sharp P, et al. Risk stratification in uncomplicated type 2 diabetes: Prospective evaluation of the combined use of coronary artery calcium imaging and selective myocardial perfusion scintigraphy. Eur Heart $\mathrm{J}$ 2006;27:713-21.

16. Cosson E, Paycha F, Paries J, Cattan S, Ramadan A, Meddah D, et al. Detecting silent coronary stenoses and stratifying cardiac risk in patients with diabetes: ECG stress test or exercise myocardial scintigraphy? Diabet Med 2004;21:342-8.

17. Faglia E, Favales F, Calia P, Paleari F, Segalini G, Gamba PL, et al. Cardiac events in 735 type 2 diabetic patients who underwent screening for unknown asymptomatic coronary heart disease: 5 -year follow-up report from the Milan Study on Atherosclerosis and Diabetes (MiSAD). Diabetes Care 2002;25:2032-6.

18. Janand-Delenne B, Savin B, Habib G, Bory M, Vague P, Lassmann-Vague V. Silent myocardial ischemia in patients with diabetes: Who to screen. Diabetes Care 1999;22:1396-400.

19. Penfornis A, Zimmermann C, Boumal D, Sabbah A, Meneveau N, Gaultier-Bourgeois S, et al. Use of dobutamine stress echocardiography in detecting silent myocardial ischaemia in asymptomatic diabetic patients: A comparison with thallium scintigraphy and exercise testing. Diabet Med 2001;18:900-5.

20. Wackers FJ, Young LH, Inzucchi SE, Chyun DA, Davey JA, Barrett EJ, et al. Detection of silent myocardial ischemia in asymptomatic diabetic subjects: The DIAD study. Diabetes Care 2004;27:1954-61.

21. Wackers FJ, Young LH. Lessons learned from the detection of ischemia in asymptomatic diabetics (DIAD) study. J Nucl Cardiol 2009;16:855-9.

22. Peix A, Cabrera L, Heres F, Rodriques L, Valdes A, et al. Interrelationship between myocardial perfusion imaging, coronary calcium score and endothelial function in asymptomatic diabetics and controls. J Nucl Cardiol 2011. doi:10.1007/s12350-0119355-2.

23. Wackers FJ, Chyun DA, Young LH, Heller GV, Iskandrian AE, Davey JA, et al. Resolution of asymptomatic myocardial ischemia in patients with type 2 diabetes in the Detection of Ischemia in Asymptomatic Diabetics (DIAD) study. Diabetes Care 2007; 30:2892-8.

24. Greenland P, Alpert JS, Beller GA, Benjamin EJ, Budoff MJ, Fayad ZA, et al. 2010 ACCF/AHA guideline for assessment of cardiovascular risk in asymptomatic adults: A report of the American College of Cardiology Foundation/American Heart Association Task Force on Practice Guidelines. Circulation 2010;122:e584-636.

25. Bansal S, Wackers FJ, Inzucchi SE, Chyun DA, Davey JA, Staib $\mathrm{LH}$, et al. Five-year outcomes in high-risk participants in the Detection of Ischemia in Asymptomatic Diabetics (DIAD) study: A post hoc analysis. Diabetes Care 2011;34:204-9. 